\title{
A Sensitive UV Spectrophotometric Method for the Determination of Gabapentin
}

\author{
R SINGH GUJRAL*, S MANIRUL HAQUE and P SHANKER \\ Vardhman Chemtech Ltd, Nimbua, Dera Bassi, Mohali (Punjab), India. \\ gujral@vardhmanchemtech.com
}

Received 1 April 2009; Accepted 5 June 2009

\begin{abstract}
An accurate and validated spectrophotometric method was developed for the determination of gabapentin. This is simple, sensitive and low cost UV spectrophotometric method. The method is based on the direct measurement of the native absorbance of the drug. The detection was done at $210 \mathrm{~nm}$. The method was linear in the range of $0.25-3.5 \mu \mathrm{g} / \mathrm{mL}$ with correlation coefficient of 0.9999 . It is validated according to the ICH guidelines with respect to linearity, selectivity, accuracy and precision, limit of quantitation and limit of detection. The method has been applied to assess gabapentin in pharmaceutical formulations with good accuracy and precision and relatively free of interference from coexisting substances.
\end{abstract}

Keywords: Gabapentin, UV, Bulk drug, Pharmaceutical formulation, Validation.

\section{Introduction}

Gabapentin (GBP), [1 - (aminomethyl) cyclohexane acetic acid [CAS NO: 60142 - 96 - 3]; is a $\gamma$ - amino butyric acid (GABA) (Figure 1) analog used for treatment of partial seizures in adults and children ${ }^{1}$. It is a valuable adjunct to other anti - epileptic drugs in adult patients who have not achieved adequate drugs control of partial seizures with these agents used alone or combination. It has a simple pharmacokinetic profile and is not protein bound. It is particularly useful in controlling secondarily generalized tonic - clonic seizures.

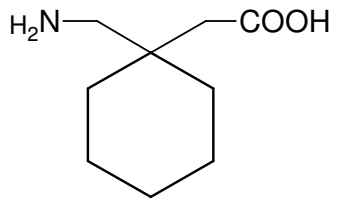

Figure 1. Structure of gabapentin. 
It has been shown that the action of GBP is possibly due to its high binding to $\alpha_{2}-\delta$ protein, an auxiliary submit of voltage - gated calcium channels. Potent binding at this reduces the release of several neurotransmitters which would reduce neuronal excitability and seizures ${ }^{2}$.

The therapeutic importance of GBP was behind the development of analytical methods for its determination. Several HPLC methods for determination of gabapentin in human plasma have been published using derivating reagents such as 2, 4, 6 - trinitrobenzene sulphonic acid $^{3,4}$ phenylisothiocyanate ${ }^{5}, o$-phthaldehyde ${ }^{6-12}$, 4-chloro-7-nitrobenzofurazan ${ }^{13,}$ 9-fluorenyl methyl chloroformate ${ }^{14}$ and 1,2-napthoquinone-4-sulphonic acid sodium salt ${ }^{15}$. A HPLC method $^{16}$ was developed for the determination of GBP, which samples requires dissolution and complex system. A spectrophotometric method ${ }^{17}$ was developed, which reaction time, wave length and LOD value is more than the proposed method. The authors had earlier reported a novel method for the determination of GBP in bulk, pharmaceutical formulation and human urine samples but it requires derivatization ${ }^{18}$.

A direct HPLC method at $215 \mathrm{~nm}$ was reported for analysis GBP in bulk drug and dosage forms in the $2008 \mathrm{USP}^{19}$. In one of the methods, spectrofluorimetric determination of GBP was reported after derivatization with fluorescamine ${ }^{20}$. In another study, colorimetric determination of gabapentin was studied based on the reaction with vanillin and ninhydrin ${ }^{21}$. A capillary electrophoresis method was also reported for determination of GBP in bulk drug and capsules ${ }^{22}$. In addition, these methods requires long and tedious pretreatment of the samples and laborious clean up procedures prior to analysis. Therefore, it is necessary to develop a simple and suitable analytical method for the determination of GBP in bulk and pharmaceutical formulations. UV-Visible spectrophotometry is the technique of choice in research laboratories, hospitals and pharmaceutical industries due to its low cost and inherent simplicity.

The aim of the present study is to develop a new method of analysis that enhances the selectivity and simplicity of the spectrophotometric methodology in UV for GBP determination in bulk and pharmaceutical formulation.

\section{Experimental}

Spectral runs were made on UV $3000^{+}$UV - VIS Spectrophotometer (LABINDIA ${ }^{\circledR}$, Mumbai, India) [Serial Number 17 - 1885 - 01 - 0016] with $1 \mathrm{~cm}$ matched glass cell.

- Gabapentin (Vardhman Chemtech Ltd, Mohali, Punjab, India) used as a working standard $(0.9923 \mathrm{mg} / \mathrm{mg})$ [Standardized with USP Gabapentin $(0.999 \mathrm{mg} / \mathrm{mg})$ Lot No G0E005.

- Pharmaceutical formulations of gabapentin such as Gabapin - 300 (Intas Pharmaceuticals, Dehradun, India), Neucobal G (Sun Pharmaceutical Industries, Jammu, India), Nurokind ${ }^{\mathrm{TM}} \mathrm{G}$ (Mankind Pharma Ltd, New Delhi, India) and Gabaneuron (Aristo Pharmaceuticals Pvt Ltd, Mumbai, India) were purchased from local markets.

\section{Standard GBP solution}

A stock solution of GBP $(100 \mu \mathrm{g} / \mathrm{mL})$ was prepared by dissolving $10 \mathrm{~g}$ GBP in $100 \mathrm{~mL}$ volumetric flasks with double distilled water. The stock solution $(100 \mu \mathrm{g} / \mathrm{mL})$ was used to prepare the working solutions by suitable dilutions with distilled water. The solutions were stable at least 20 days in room temperature. 


\section{Procedure for determination of $G B P$}

Aliquots of stock solution $(100 \mu \mathrm{g} / \mathrm{mL})$ were transferred into a set of $50 \mathrm{~mL}$ volumetric flasks and volumes were completed to the mark with distilled water to produce solutions in the concentration range $0.25-3.50 \mu \mathrm{g} / \mathrm{mL}$. Absorbance was measured at $210 \mathrm{~nm}$ against the reagent blank. Calibration graphs were constructed by plotting absorbance against the final concentration of GBP.

\section{Procedure for determination of GBP in pharmaceutical formulations}

One capsule (claiming $300 \mathrm{~g}$ of Gabapentin) was accurately weighed and finely powdered. A quantity of the powder equivalent to $50 \mathrm{~g}$ of GBP was extracted by shaking with $20 \mathrm{~mL}$ of distilled water, followed by another two extractions each with $10 \mathrm{~mL}$ distilled water. After passing through a $0.45 \mu \mathrm{m}$ millipore filter, the solution was diluted with distilled water to obtain a concentration of about $100 \mu \mathrm{g} / \mathrm{mL}$. It was further diluted according to the need and then analyzed following the proposed procedures. The nominal content of the capsule was calculated either from the previously plotted calibration graphs or using regression equation.

\section{Evaluation of bias}

The bias has been evaluated by means of point and interval hypothesis tests ${ }^{23-24}$. In interval hypothesis the proposed method is accepted when the true mean is within $\pm 2 \%$ of that of the reference method, i.e. $0.98<\mu_{2} / \mu_{1}<1.02$ Which can be generalized to $\theta_{\mathrm{L}}<\mu_{2} / \mu_{1}<\theta_{\mathrm{U}}$ where $\theta_{\mathrm{L}}$ and $\theta_{\mathrm{U}}$ are lower and upper acceptance limits, respectively.

\section{Results and Discussion}

\section{Linearity}

Aqueous solution of gabapentin was measured at $210 \mathrm{~nm}$ against the reagent blank Figure 2. Based on its inherent absorbance property, direct determination of GBP was achieved in pharmaceutical formulations. A calibration curve was constructed by plotting the absorbance versus final concentration of GBP, which showed a linear response showing the linear dynamic range over the concentration range $0.25-3.5 \mu \mathrm{g} / \mathrm{mL}$ Figure 3. Linear regression analysis of calibration data gave the regression equations cited in Table 1 with correlation coefficients close to unity.

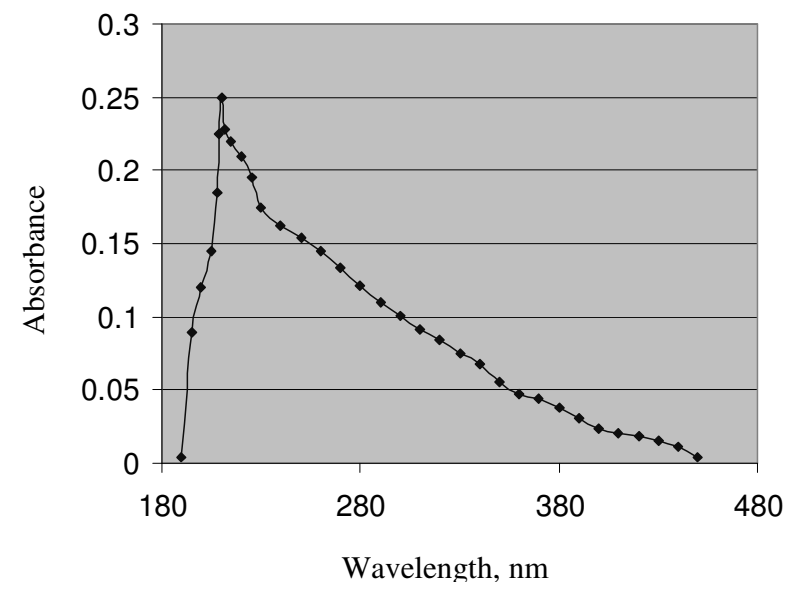

Figure 2. Absorption spectra of gabapentin $(2.5 \mu \mathrm{g} / \mathrm{mL})$. 


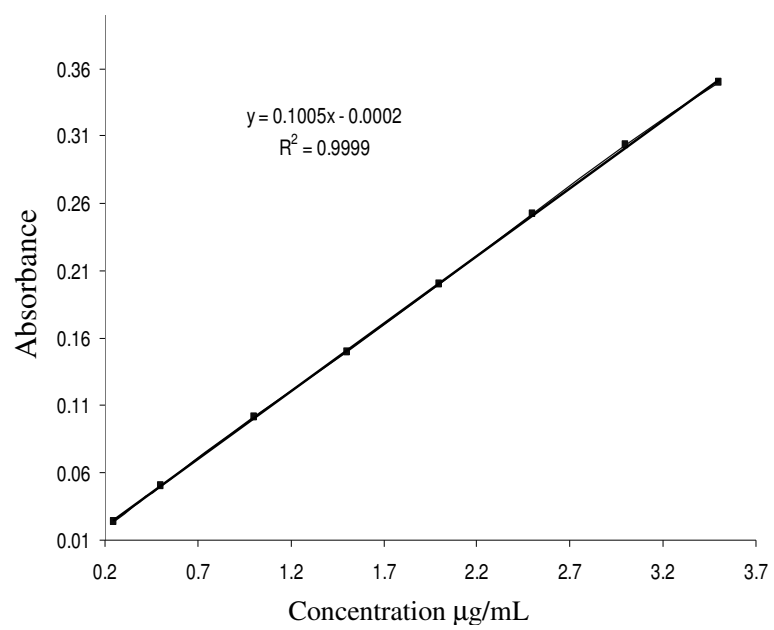

Figure 3. Linearity of absorbance corresponding the concentration of the proposed method.

Table 1. Summary of optical and regression characteristics of the proposed method.

\begin{tabular}{ll}
\hline \multicolumn{1}{c}{ Parameters } & Gabapentin \\
\hline Linear dynamic range, $\mu \mathrm{g} / \mathrm{mL}_{\text {Regression equation }^{\mathrm{a}}}$ & $0.25-3.50$ \\
$\mathrm{~S}_{\mathrm{a}}$ & $\mathrm{Y}=1.005 \times 10^{-1} \mathrm{x}-2.0 \times 10^{-4}$ \\
$\mathrm{~S}_{\mathrm{b}}$ & $9.05 \times 10^{-4}$ \\
Correlation coefficient $(\mathrm{r})$ & $4.32 \times 10^{-4}$ \\
$\mathrm{LOD}, \mu \mathrm{g} / \mathrm{mL}$ & 0.9999 \\
$\mathrm{LOQ}, \mu \mathrm{g} / \mathrm{mL}$ & $4.40 \times 10^{-2}$ \\
Variance $\left(\mathrm{S}_{\mathrm{o}}{ }^{2}\right)$ of calibration line & $1.33 \times 10^{-1}$ \\
\hline
\end{tabular}

${ }^{a}$ With respect to $Y=a+b X$, where $X$ is the concentration in $\mu \mathrm{g} / \mathrm{mL}, Y$ is Absorbance; ${ }^{b}$ Confidence interval of the intercept and slope at $95 \%$ confidence level and ten degrees of freedom $(t=2.228)$

\section{Specificity and selectivity}

The working standard and pharmaceutical formulation sample solutions were stressed by light and heat (up to $50{ }^{\circ} \mathrm{C}$ ) for 3 hours. It was observed that stress by such conditions did not cause significant degradation. There is no change in the absorption spectra. All stressed samples (light and heat) and unstressed sample solutions were analyzed for the active content of GBP, which gave acceptable recoveries of the drug. The influence of frequently encountered excipients in pharmaceutical formulations of GBP on the proposed method was studied by adding different amounts of possible interferents to the sample. It was observed that glucose, fructose, sucrose, cellulose, starch, lactose, magnesium stearate, sodium stearyl fumarate, red oxide of iron and Ponceau 4R \& Titanium dioxide did not interfere the proposed method.

\section{Accuracy and precision}

The accuracy and precision of the proposed method was established by performing intraday and interday assays by determining the content of GBP in bulk and pharmaceutical formulation samples at three different concentration levels (low, medium and high). These assays were investigated by measuring five independent analyses at $1,2 \& 3 \mu \mathrm{g} / \mathrm{mL}$ concentration levels within 1 day and on 5 consecutive days, respectively Table $2 \& 3$. The standard deviation, relative standard deviation and standard analytical error obtained by both methods are acceptable i.e. within the permissible bias range and therefore can be considered to be satisfactory. 
Table 2. Summary of accuracy and precision results of the proposed method in pure form.

\begin{tabular}{|c|c|c|c|c|c|c|}
\hline \multirow{2}{*}{$\begin{array}{l}\text { Proposed } \\
\text { methods }\end{array}$} & \multicolumn{2}{|c|}{ Amount, $\mu \mathrm{g} / \mathrm{mL}$} & \multirow{2}{*}{ RSD, \% } & \multirow{2}{*}{ REC, \% } & \multirow{2}{*}{$\mathrm{SAE}^{\mathrm{b}}$} & \multirow{2}{*}{ C.L. ${ }^{\mathrm{c}}$} \\
\hline & Taken & Found $\pm \mathrm{SD}^{\mathrm{a}}$ & & & & \\
\hline \multirow{3}{*}{ Intraday assay } & 1.00 & $0.9992 \pm 0.002$ & 0.204 & 99.920 & $9.1 \times 10^{-4}$ & $2.5 \times 10^{-3}$ \\
\hline & 2.00 & $1.9999 \pm 0.003$ & 0.136 & 9.950 & $1.2 \times 10^{-3}$ & $3.4 \times 10^{-3}$ \\
\hline & 3.00 & $2.9999 \pm 0.005$ & 0.165 & 99.954 & $2.2 \times 10^{-3}$ & $6.2 \times 10^{-3}$ \\
\hline \multirow[t]{3}{*}{ Interday assay } & 1.00 & $0.9998 \pm 0.004$ & 0.362 & 99.920 & $1.6 \times 10^{-3}$ & $4.5 \times 10^{-3}$ \\
\hline & 2.00 & $1.9998 \pm 0.003$ & 0.147 & 9.990 & $1.3 \times 10^{-3}$ & $3.6 \times 10^{-3}$ \\
\hline & 3.00 & $2.9988 \pm 0.007$ & 0.229 & 99.960 & $3.1 \times 10^{-3}$ & $8.5 \times 10^{-3}$ \\
\hline
\end{tabular}

${ }^{a}$ Mean for 5 independent analyses. ${ }^{b}$ SAE, standard analytical error. ${ }^{c} C . L$, confidence limit at $95 \%$ confidence level and 4 degrees of freedom $(t=2.776)$.

Table 3. Summary of accuracy and precision results of the proposed method in pharmaceutical formulations.

\begin{tabular}{|c|c|c|c|c|c|c|}
\hline \multirow{2}{*}{$\begin{array}{l}\text { Proposed } \\
\text { methods }\end{array}$} & \multicolumn{2}{|c|}{ Amount, $\mu \mathrm{g} / \mathrm{mL}$} & \multirow{2}{*}{$\begin{array}{c}\mathrm{RSD}, \\
\%\end{array}$} & \multirow[t]{2}{*}{ REC, \% } & \multirow[t]{2}{*}{$\mathrm{SAE}^{\mathrm{b}}$} & \multirow[t]{2}{*}{ C.L. ${ }^{c}$} \\
\hline & Taken & Found $\pm \mathrm{SD}^{\mathrm{a}}$ & & & & \\
\hline \multicolumn{7}{|l|}{ Intraday assay } \\
\hline \multirow[t]{3}{*}{ Gabapin } & 1.00 & $0.999 \pm 0.006$ & 0.579 & 99.940 & 0.0026 & 0.0072 \\
\hline & 2.00 & $1.999 \pm 0.002$ & 0.119 & 99.990 & 0.0011 & 0.0030 \\
\hline & 3.00 & $2.999 \pm 0.003$ & 0.101 & 99.987 & 0.0014 & 0.0038 \\
\hline \multirow[t]{3}{*}{ Neucobal G } & 1.00 & $0.999 \pm 0.002$ & 0.181 & 99.940 & 0.0008 & 0.0022 \\
\hline & 2.00 & $2.000 \pm 0.004$ & 0.188 & 100.020 & 0.0017 & 0.0047 \\
\hline & 3.00 & $3.002 \pm 0.004$ & 0.127 & 100.007 & 0.0017 & 0.0047 \\
\hline \multirow[t]{3}{*}{ Nurokind ${ }^{\mathrm{TM}} \mathrm{G}$} & 1.00 & $0.999 \pm 0.003$ & 0.294 & 99.980 & 0.0013 & 0.0036 \\
\hline & 2.00 & $2.000 \pm 0.005$ & 0.232 & 100.020 & 0.0021 & 0.0058 \\
\hline & 3.00 & $2.999 \pm 0.002$ & 0.055 & 99.993 & 0.0007 & 0.0020 \\
\hline \multirow[t]{3}{*}{ Gabaneuron } & 1.00 & $1.000 \pm 0.002$ & 0.244 & 100.00 & 0.0011 & 0.0030 \\
\hline & 2.00 & $1.999 \pm 0.003$ & 0.138 & 99.990 & 0.0012 & 0.0034 \\
\hline & 3.00 & $2.999 \pm 0.003$ & 0.103 & 99.993 & 0.0014 & 0.0038 \\
\hline \multicolumn{7}{|c|}{ Interday assay } \\
\hline \multirow[t]{3}{*}{ Gabapin } & 1.00 & $0.999 \pm 0.004$ & 0.413 & 99.980 & 0.0019 & 0.0053 \\
\hline & 2.00 & $1.999 \pm 0.004$ & 0.210 & 99.980 & 0.0019 & 0.0053 \\
\hline & 3.00 & $2.999 \pm 0.004$ & 0.148 & 99.987 & 0.0020 & 0.0056 \\
\hline \multirow[t]{3}{*}{ Neucobal G } & 1.00 & $0.999 \pm 0.005$ & 0.461 & 99.999 & 0.0021 & 0.0058 \\
\hline & 2.00 & $1.999 \pm 0.005$ & 0.237 & 99.990 & 0.0021 & 0.0058 \\
\hline & 3.00 & $2.999 \pm 0.004$ & 0.140 & 99.993 & 0.0019 & 0.0053 \\
\hline \multirow[t]{3}{*}{ Nurokind ${ }^{\mathrm{TM}} \mathrm{G}$} & 1.00 & $1.000 \pm 0.003$ & 0.340 & 100.020 & 0.0015 & 0.0042 \\
\hline & 2.00 & $1.999 \pm 0.005$ & 0.237 & 99.990 & 0.0021 & 0.0058 \\
\hline & 3.00 & $3.000 \pm 0.004$ & 0.116 & 100.013 & 0.0016 & 0.0043 \\
\hline \multirow[t]{3}{*}{ Gabaneuron } & 1.00 & $0.999 \pm 0.005$ & 0.460 & 99.940 & 0.0021 & 0.0058 \\
\hline & 2.00 & $1.999 \pm 0.005$ & 0.267 & 99.990 & 0.0024 & 0.0067 \\
\hline & 3.00 & $2.999 \pm 0.006$ & 0.211 & 99.987 & 0.0028 & 0.0078 \\
\hline
\end{tabular}

${ }^{a}$ Mean for 5 independent analyses. ${ }^{b} S A E$, standard analytical error. ${ }^{c}$ C.L., confidence limit at $95 \%$ confidence level and 4 degrees of freedom $(t=2.776)$. 
Standard addition method was employed to check the validity of the proposed procedures. In this method, a known amount of pure GBP was added to its formulated capsules at different concentration levels and the nominal value of the drug was calculated following the proposed procedure. The results are summarized in Table 4. As can be seen from the Table 4 that recovery obtained by the proposed procedure is quite satisfactory with low RSD.

Table 4. Summary of data for the determination of gabapentin in pharmaceutical preparations by standard addition method.

\begin{tabular}{ccccccc}
\hline \multirow{2}{*}{ Formulations } & \multicolumn{3}{c}{ Amount, $\mu \mathrm{g} / \mathrm{mL}$} & Recovery & RSD & SAE $^{\mathrm{b}}$ \\
\cline { 2 - 4 } & Taken & Added & Found $\pm \mathrm{SD}^{\mathrm{a}}$ & $\%$ & \\
\hline Gabapin & 0.50 & 0.25 & $0.750 \pm 0.002$ & 100.007 & 0.255 & 0.0009 \\
& 0.50 & 1.00 & $1.500 \pm 0.003$ & 100.007 & 0.218 & 0.0015 \\
& 0.50 & 2.00 & $2.499 \pm 0.003$ & 99.996 & 0.134 & 0.0015 \\
Neucobal G & 0.50 & 3.00 & $3.500 \pm 0.003$ & 100.003 & 0.069 & 0.0011 \\
& 0.50 & 0.25 & $0.750 \pm 0.004$ & 100.007 & 0.518 & 0.0017 \\
& 0.50 & 1.00 & $1.500 \pm 0.005$ & 100.007 & 0.320 & 0.0022 \\
Nurokind ${ }^{\mathrm{TM}} \mathrm{G}$ & 0.50 & 2.00 & $2.499 \pm 0.004$ & 99.996 & 0.168 & 0.0019 \\
& 0.50 & 3.00 & $3.500 \pm 0.003$ & 100.003 & 0.091 & 0.0014 \\
& 0.50 & 0.25 & $0.750 \pm 0.002$ & 100.007 & 0.197 & 0.0007 \\
& 0.50 & 2.00 & $2.499 \pm 0.004$ & 99.988 & 0.172 & 0.0019 \\
Gabaneuron & 0.50 & 3.00 & $3.499 \pm 0.005$ & 99.997 & 0.146 & 0.0023 \\
& 0.50 & 0.25 & $0.750 \pm 0.004$ & 100.060 & 0.542 & 0.0018 \\
& 0.50 & 1.00 & $1.499 \pm 0.006$ & 99.993 & 0.371 & 0.0025 \\
& 0.50 & 2.00 & $2.500 \pm 0.003$ & 100.004 & 0.134 & 0.0015 \\
& 0.50 & 3.00 & $3.500 \pm 0.005$ & 100.003 & 0.128 & 0.0020 \\
\hline
\end{tabular}

${ }^{a}$ Mean for 5 independent analyses. ${ }^{b} S A E$, standard analytical error.

\section{Applicability of the proposed method}

The applicability of the proposed method for the assay of GBP in drug formulations has been tested on commercially available capsules. The results of the proposed method were statistically compared with those of the developed reference method using point and interval hypothesis tests. Table 5 shows that the calculated ( $t$-paired) and $F$-values at $95 \%$ confidence level are less than the theoretical ones, confirming no significant difference between the methods compared. It can also be seen from Table 5 that the bias evaluated by interval hypothesis test is within the acceptable range of $\theta_{\mathrm{L}}=$ 0.98 and $\theta_{\mathrm{U}}=1.02$.

The performance of the proposed method was compared with other method Table 6 . It can be seen from Table 6 that HPLC methods ${ }^{25,26}$ were time consuming and tedious but precision are also somewhat poor. UV method ${ }^{17}$ is sensitive but RSD values are higher. The present method is simple, fast and accurate because it does not involve any pretreatment step prior to analysis. 
Table 5. Assay results of GBP in commercial capsules using the proposed method and reference method $^{19}$

\begin{tabular}{lll}
\hline Formulations & Proposed method & Reference method \\
\hline Gabapin 300 & & \\
Recovery, \% & 99.997 & 99.908 \\
RSD & 0.104 & 0.567 \\
t & 0.48 & \\
F & 3.35 & \\
$\theta_{\mathrm{L}}$ & 0.993 & \\
$\theta_{\mathrm{U}}$ & 1.004 & \\
\hline
\end{tabular}

Table 6. Comparisons of the proposed method with other existing methods for the assay of gabapentin in pharmaceutical formulations.

\begin{tabular}{cccccccc}
\hline Reagents & $\begin{array}{c}\lambda_{\max }, \\
\mathrm{nm}\end{array}$ & $\begin{array}{c}\text { Linear } \\
\text { Dynamic } \\
\text { Range, } \\
\mu \mathrm{g} / \mathrm{mL}\end{array}$ & RSD & LOD & LOQ & $\mathrm{R}^{2}$ & Reference \\
\hline FDNB & 360 & $10-500$ & 1.11 & 3.21 & 9.73 & 0.9998 & 25 \\
Fluorescamine & - & $0.2-10$ & 4.51 & 0.11 & 0.35 & 0.9954 & 26 \\
TCNQ & 842 & $8-24$ & 1.40 & 0.48 & 1.60 & 0.9997 & 17 \\
DDQ & 456 & $12-36$ & 1.70 & 1.20 & 3.99 & 0.9993 & 17 \\
pCA & 535 & $60-200$ & 0.94 & 7.59 & 25.30 & 0.9991 & 17 \\
Chloranil & 521 & $40-120$ & 0.84 & 3.33 & 11.10 & 0.9995 & 17 \\
Iodine & 360 & $6-30$ & 0.93 & 0.39 & 1.31 & 0.9998 & 17 \\
TCNE & 412 & $40-140$ & 1.10 & 3.54 & 11.80 & 0.9994 & 17 \\
- & 210 & $0.25-3.50$ & 0.136 & 0.044 & 0.133 & 0.9999 & This work \\
\hline
\end{tabular}

\section{References}

1. Walker M C and Patsalos P N, Pharmacol Ther., 1995, 67, 351-384.

2. Taylor C P, Angelotti T and Fauman E, Epilepsy Res., 2007, 73, 137-150.

3. Hengy H and Kolle E U, J Chromatogr B., 1985, 341, 473-478.

4. Juenke J M, Brown P I, McMilllin G A and Urry F M, Clin Chem., 2003, 49, 1198-1201.

5. Zhu Z and Neirinck L, J Chromatogr B., 2002, 779, 307-312.

6. Forrest G, Sills G L, Leach J P and. Brodie M J, J Chromatogr B., 1996, 681, 421-425.

7. Ratnaraj H and Patsalos P N, Ther Drug Monit., 1998, 20, 430-434.

8. Jiang Q and Li S, J Chromatogr B., 1999, 727, 119-123.

9. Tang P H, Miles M V, Glauser T A and Grauw T D, J Chromatogr B., 1999, 727, 125-129.

10. Chollet D F, Goumag L, Juliano C and Anderegg G, J Chromatogr B., 2000, 746, 311-314.

11. Gauthier J D and Gupta R, Clin Chem., 2002, 48, 2259-2261.

12. Vermeij T A C and Edelbrock P M, J Chromatogr B., 2004, 810, 297-303.

13. Bahrami G and Mohammadi B, J Chromatogr B., 2006, 837, 24-28.

14. Bahrami G and Kiani A, J Chromatogr B., 2006, 835, 123-126.

15. Sagirli O, Cetin S M. and Onal A, J Pharm Biomed Anal., 2006, 42, 618-624.

16. Gupta A, Ciavarella A B, Sayeed V A, Khan M A and Faustino P J, J Pharm Biomed Anal., 2008, 46, 181-186. 
17. Salem H, African J Pharm Pharmaco., 2008, 2(7), 136-144.

18. Gujral R S and Haque S M, Int J Biomed Sci., 2009, 5, 100-106.

19. The United States Pharmacopeia, Asian Edition, United States Pharmacopeial Convention, Inc.; Twin brook Parkway, Rockville, $31^{\text {th }}$ Revision MD, 2008, p. 2241.

20. Belal F, Abdine H, Al-Majed A and Khalil N Y, J Pharm Biomed Anal., 2002, 27, 253- 260.

21. Abdellatef H E and Khalil H M, J Pharm Biomed Anal., 2003, 31, 209-214.

22. Sekar R and Azhaguvel S, J Pharm Biomed Anal., 2004, 36, 663 - 667.

23. Hartmann C, Smeyers - Verbeke J, Peninckx W, Heyden Y. V, Venkeerghen P and Massart D L, Anal Chem., 1995, 67, 4491- 4499.

24. Canada Health Protection Branch, Drugs Directorate guidelines, Acceptable methods, Ministry of National Health and Welfare, Draft, Ottawa, Canada, 1992.

25. Souri E, Jalalizadeh H and Shafiee A, Chem Pharm Bull., 2007, 55, 1427-1430.

26. Al-Majed A A, J Liq Chrom Relat Tech., 2005, 28, 3119-3129. 


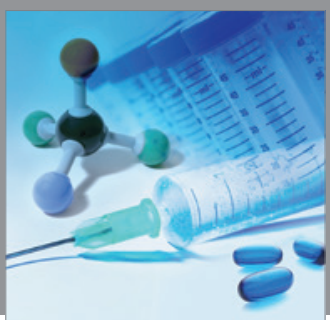

International Journal of

Medicinal Chemistry

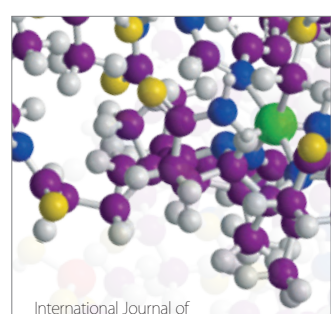

Carbohydrate Chemistry

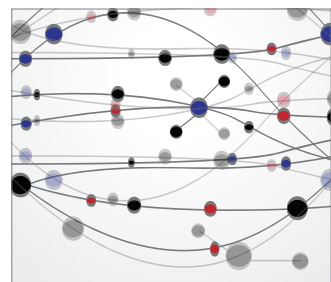

The Scientific World Journal
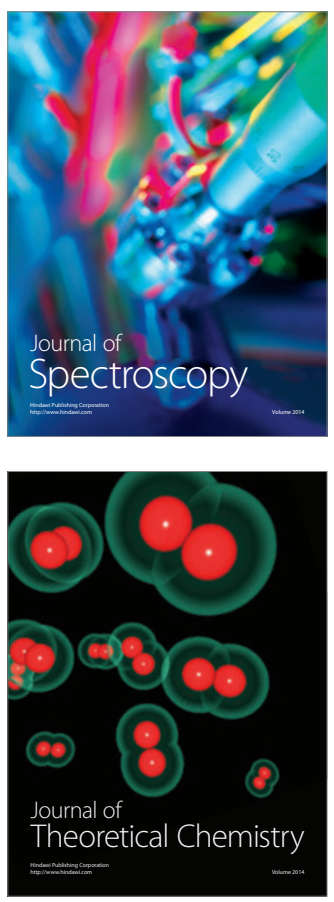
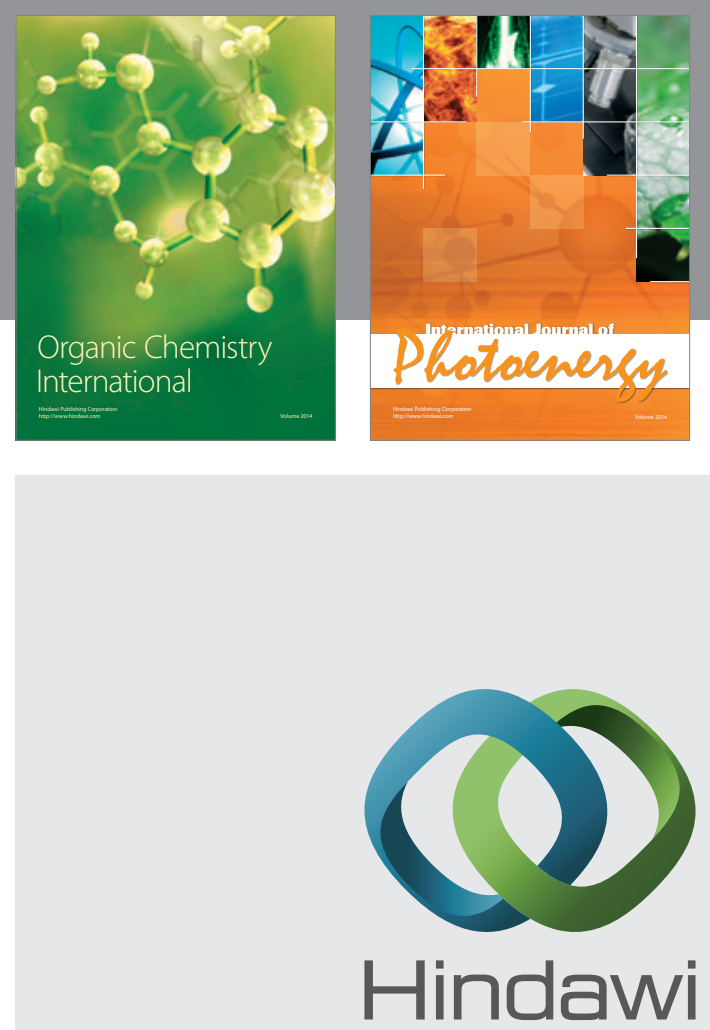

Submit your manuscripts at

http://www.hindawi.com
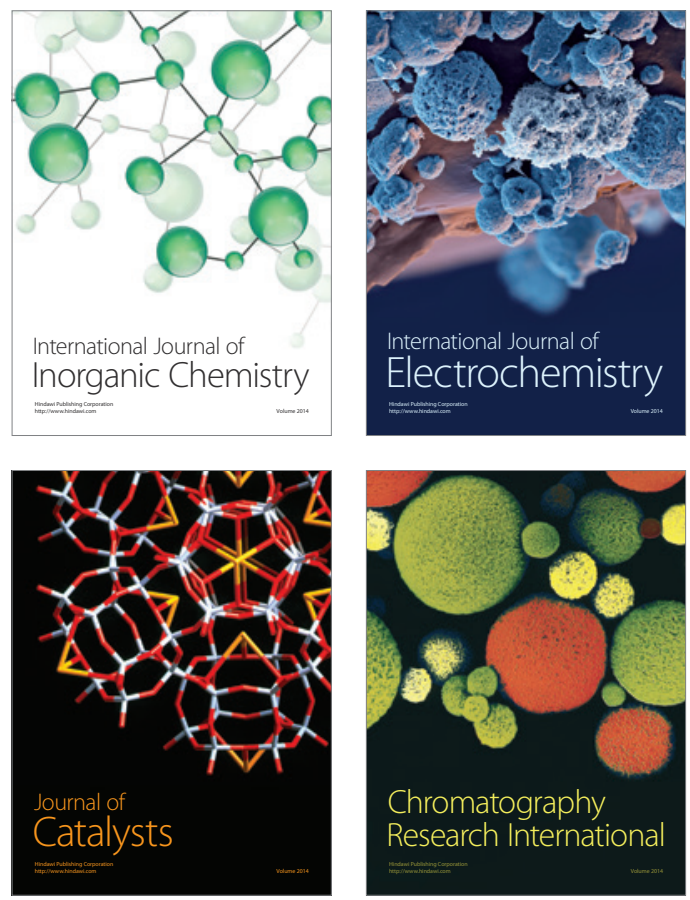
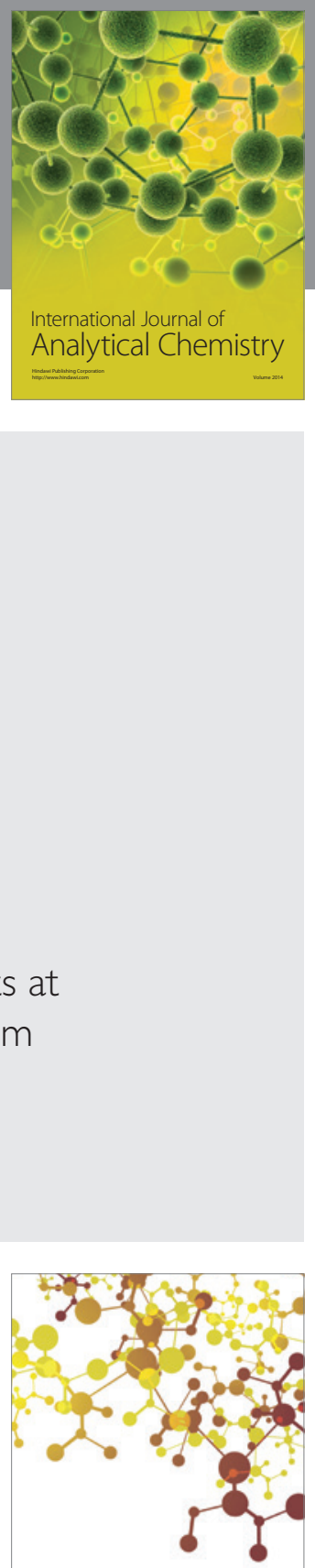

Journal of

Applied Chemistry
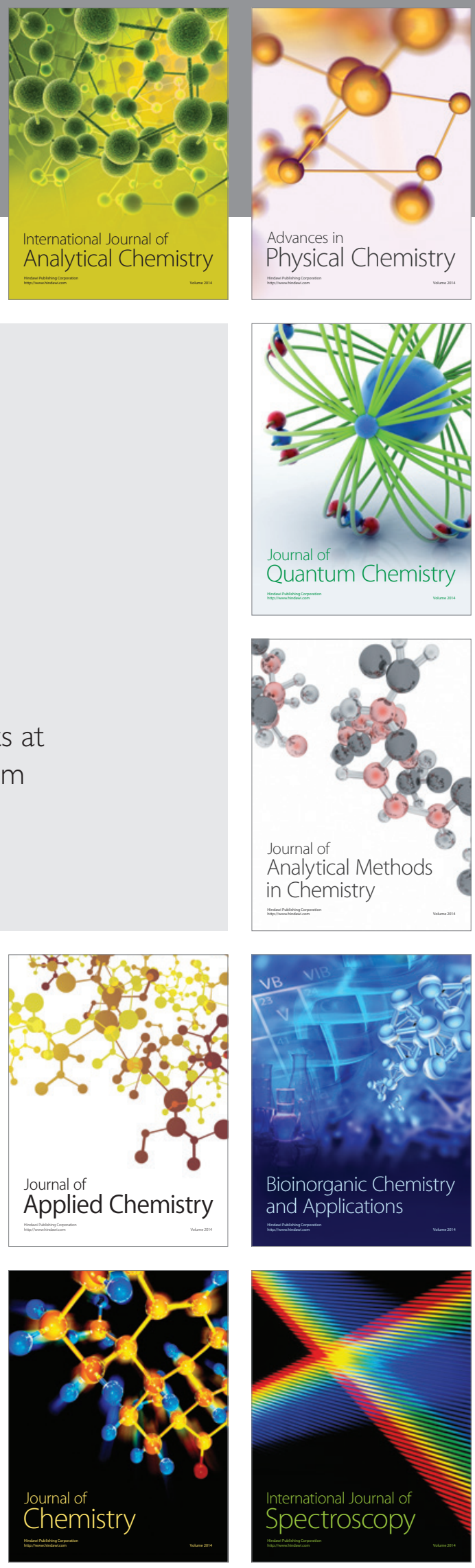